Artigo Original

\title{
Gait Characteristics in People with Diabetes Classified in Risk Categories 0 and 2 of the IWGDF: International Working Group on the Diabetic Foot
}

\author{
Maria António Castro a,b,*, Pedro Fonseca ${ }^{\mathrm{c}}$, Fernando Paiotti ${ }^{\mathrm{d}}$, Margarida Pocinho ${ }^{\mathrm{b}}$, \\ Davide Carvalho a,e, Eduardo Vinha ${ }^{\mathrm{a}, \mathrm{e}}$, João Paulo Vilas-Boas ${ }^{\mathrm{c}, \mathrm{f}}$ \\ ${ }^{a}$ Faculdade de Medicina, Universidade do Porto, Porto, Portugal \\ ${ }^{b}$ School of Health Sciences, Polytechnic of Leiria and Centre for Mechanical Engineering, Materials and Processes (CEMMPRE), Coimbra's University, Coimbra, Portugal \\ LABIOMEP - Porto Biomechanics Laboratory - University of Porto, Porto, Portugal \\ ${ }^{d}$ Escola de Educação Física e Esporte da Universidade de São Paulo, São Paulo, Brasil \\ e Department of Endocrinology, Diabetes and Metabolism, Centro Hospitalar de São João, Porto, Portugal \\ ${ }^{f}$ Faculty of Sport, CIFI2D, University of Porto, Porto, Portugal
}

\section{INFORMAÇÃO SOBRE O ARTIGO}

Historial do artigo:

Received/ Recebido: 2020-08-28

Accepted/Aceite: 2021-19-29

Publicado / Published: 2022-01-24

(C) Autor (es) (ou seu (s) empregador (es)) e Revista SPEDM 2021. Reutilização permitida de acordo com CC BY-NC. Nenhuma reutilização comercial.

(C) Author(s) (or their employer(s)) and SPEDM Journal 2021. Re-use permitted under CC BY-NC.

No commercial re-use.

\section{Palavras-chave:}

Complicações da Diabetes;

Diabetes Mellitus;

Marcha;

Neuorpatias Diabéticas.

\section{R E S U M O}

Introdução: Metade dos doentes com diabetes há mais de 20 anos desenvolve neuropatia periférica, que leva a distúrbios biomecânicos, principalmente nos membros inferiores. A avaliação da marcha pode ser útil para detetar o impacto da diabetes na marcha e no desempenho dos membros inferiores em estádios iniciais.

Este estudo tem como objetivo caracterizar a marcha de pessoas com diabetes classificadas nas categorias 0 e 2 do Sistema de Classificação de Risco do International Working Group on the Diabetic Foot (IWGDF).

Métodos: Foram avaliados com um sistema de análise de movimento tridimensional de corpo inteiro, 122 ensaios de marcha de 10 doentes com diabetes.

Resultados: O grupo sem neuropatia periférica apresenta marcha mais rápida, com maior cadência, maior comprimento da passada e do passo e menos tempo de apoio duplo e de largura da passada. $\mathrm{O}$ grupo de neuropatia periférica mostra uma tendência para produzir uma força de reação ao solo de menor amplitude (Pillai's Trace $=0,913 ; \mathrm{F}(18,40)=23,466 ; p<0,0001$ ), e mais tardiamente (Pillai's Trace $=0.743 ; \mathrm{F}(18,40)=6,436 ; p<0,0001)$.

Os parâmetros espaciotemporais da marcha, facilmente avaliados na consulta, como a largura e o comprimento da passada, a duração do ciclo da marcha e a fase de apoio duplo do membro, bem como a velocidade da marcha e as estaturas por segundo, podem predizer $58 \%(\mathrm{~F}=26,558$; $p<0,0001)$ a neuropatia periférica.

Conclusão: Este estudo destaca as diferenças biomecânicas na marcha de pessoas com diabetes classificadas em diferentes grupos de risco, e a importância dos parâmetros espaciotemporais da marcha para identificar o risco de neuropatia periférica.

\section{Características da Marcha em Pessoas com Diabetes Classificadas nas Categorias de Risco 0 e 2 do IWGDF: International Working Group on the Diabetic Foot}

\section{A B S T R A C T}

Introduction: Half the patients who have had diabetes for more than 20 years develop peripheral neuropathy, which leads to biomechanical disorders, particularly in the lower limbs. Gait assessment may be useful to detect diabetes impact on walking and limbs performance in an early stage.

This study aims to characterize the gait of people with diabetes classified in categories 0 and 2 of the

\footnotetext{
* Autor Correspondente / Corresponding Author.

E-Mail: macastro@netcabo.pt; maria.castro@ipleiria.pt (Maria António Castro)

Escola Superior de Saúde, Campus 2 - Morro do Lena - Alto do Vieiro - Apartado 4137

2411-901 Leiria, Portugal
} 
International Working Group on the Diabetic Foot (IWGDF) Risk Classification System. Methods: One hundred twenty two full-body walking trials of 10 patients with diabetes were analyzed with a Motion Capture system.

Results: The group without peripheral neuropathy shows a faster gait with higher cadence, greater stride and step length and less double stance time and stride width. Peripheral neuropathy group shows a trend to produce lower amplitude Ground Reaction force (Pillai's Trace $=0.913$; $\mathrm{F}(18.40)=23.466 ; p<0.0001$ ), and later in time (Pillai's Trace $=0.743 ; \mathrm{F}(18.40)=6.436 ; p<0.0001$ ). Gait spatiotemporal parameters, that are easily assessed in a clinical consultation, such as the stride width and length, the duration of the gait cycle and the double limb support phase, as well as the gait speed and the statures per second, can predict $58 \%(\mathrm{~F}=26.558 ; p<0.0001)$ the peripheral neuropathy. Conclusion: This study highlights the biomechanics differences in the gait of people with diabetes classified in different risk groups, and the importance of spatiotemporal gait parameters to identify the risk of peripheral neuropathy.

\section{Introduction}

Diabetes mellitus, considered epidemic by the World Health Organization (WHO), is a metabolic and chronic disease that constitutes the greatest cause of mortality worldwide, not only due to the disease but also to its complications, ${ }^{1}$ such as polyneuropathy, retinopathy and peripheral artery disease. Often these complications are present when the disease is diagnosed, suggesting that micro- or macrovascular complications in different systems, already occur in the early stages of diabetes. ${ }^{2}$

Neuropathy alters peripheral nerve function, affecting sensitivity, especially in the lower limbs. This sensorial loss leads to skin-level injuries such as pressure ulcers, which may progress to amputation with a great impact on patients' quality of life. Several other impairments in muscle strength, and consequently in the range of motion and motor control have been associated with diabetes progression. ${ }^{3,4}$ According to the International Working Group on Diabetic Foot (IWGDF), peripheral neuropathy is the most important risk factor for the development of ulcers in patients with diabetes. ${ }^{5}$ About $50 \%$ of patients who have had diabetes for more than 20 years develop peripheral neuropathy, which can affect nerve function from peripheral to more proximal regions. ${ }^{6}$ Peripheral neuropathy is expected to lead to biomechanical disorders, particularly at the lower limbs, and these may contribute to the development of plantar foot ulceration in people with diabetes. ${ }^{4}$ Most of the studies on this matter have compared diabetic patients with normal controls ${ }^{7}$ which reveal, as expected, a difference on most measured parameters that focus especially on vertical kinetic parameters and gait progression plane. ${ }^{8}$ Few studies compare kinematics in patients with and without peripheral neuropathy and there is a significant variation in methods and results between them. ${ }^{9}$ Diabetes-related lower extremity altered biomechanics relies on an appropriate understanding of lower extremity kinematics and kinetics to better inform clinicians of the disease progression and the consequent implementation of prevention measures. Gait assessment may be useful to detect, in an early stage, diabetes impact on walking and lower limb performance ${ }^{10}$ thus contributing to prevent gait disorders and the risk of falls. ${ }^{9}$

This study aims to characterize the gait of people with diabetes classified in categories 0 and 2 of the IWGDF Risk Classification System. ${ }^{5}$

\section{Material and Methods Participants}

One hundred and twenty-two walking trials of ten patients (8 males and 2 females) with diabetes, classified in categories 0 and 2 of the 2015 IWGDF Risk Classification System were studied. Patients were selected from the diabetes outpatient clinic during the study time based on the risk classification and distributed in two groups: no peripheral neuropathy $(0)$ and peripheral neuropathy with peripheral arterial disease and/or a foot deformity (2). Participants' characteristics in each group of diabetic foot classification are resumed in Table 1 for that no statistical differences were found.

Diagnosis of neuropathy was based on medical assessment and included monofilament test, vibration test with biosthiometer, deep tendon reflexes and autonomic testing in addition to glycated Hemoglobin (HbA1c), transcutaneous oxygen pressure and ankle-brachial index. Michigan Neuropathy Screening Instrument previously validated to the Portuguese population ${ }^{11}$ was also performed.

Exclusion criteria, based on medical history, were the presence of any disturbance that might affect the gait like an orthopedic, neurological or visual impairment or other, including current injury, pain, active ulceration, or previous amputation.

The study was conducted at LABIOMEP - Porto University Biomechanics Laboratory after approval of the Ethics Committee

Table 1. Participants characteristics in both groups 0 and 2 IWGDF.

\begin{tabular}{|c|c|c|c|c|c|c|c|}
\hline & \multicolumn{7}{|c|}{ IWGDF Risk Classification } \\
\hline & \multicolumn{3}{|c|}{$\begin{array}{l}\text { (0) no peripheral neuropathy } \\
\text { (N=5; } 1 \text { Women, } 4 \text { Men) }\end{array}$} & \multicolumn{3}{|c|}{$\begin{array}{l}\text { (2) peripheral neuropathy with peripheral } \\
\text { arterial disease and/or a foot deformity } \\
(\mathrm{N}=5 ; 1 \text { Women, } 4 \text { Men) }\end{array}$} & \multirow{3}{*}{$p$} \\
\hline & \multirow{2}{*}{ Median } & \multicolumn{2}{|c|}{ Quartiles } & \multirow{2}{*}{ Median } & \multicolumn{2}{|c|}{ Quartiles } & \\
\hline & & 25 & 75 & & 25 & 75 & \\
\hline Age (years) & 40.5 & 18.8 & 61.7 & 61.3 & 55.2 & 75.4 & 0.15 \\
\hline Height (m) & 1.7 & 1.5 & 1.8 & 1.7 & 1.6 & 1.7 & 0.84 \\
\hline Weight $(\mathrm{Kg})$ & 65.0 & 57.8 & 83.5 & 85.0 & 79.8 & 91.5 & 0.10 \\
\hline $\mathrm{BMI}\left(\mathrm{Kgm}^{-2}\right)$ & 23.1 & 22.2 & 28.7 & 29.4 & 28.8 & 33.6 & 0.06 \\
\hline Diabetes duration (years) & 11.0 & 9.0 & 20.0 & 10.0 & 8.0 & 30.0 & 0.69 \\
\hline
\end{tabular}


of São João Hospital and Faculty of Medicine of the University of Porto. Only the subjects that consented to participate after the procedures/steps explanation were assigned to the study.

\section{Gait assessment}

An 11-camera Qualisys motion capture (MoCap) system (Qualisys $\mathrm{AB}$, Sweden), operating at a $200 \mathrm{~Hz}$ sampling frequency, was used to track the displacement of 77 retroreflective markers that comprised a full-body marker setup based on the Institute Orthopedic Rizzoli (IOR) model. ${ }^{12-14}$ Marker clusters were also placed over the thighs and shanks to improve the segment tracking accuracy. ${ }^{13}$ Kinematic data were collected in a previously calibrated volume with a calibration error below $0.7 \mathrm{~mm}$.

Ground reaction forces were measured by four Bertec (Bertec Corporation, USA) force platforms (2 platforms of 40x60 $\mathrm{cm}$ and 2 platforms of $60 \times 90 \mathrm{~cm}$ ) recording at a $2000 \mathrm{~Hz}$ sampling rate. The arrangement of force platforms allowed for the measurement of three consecutive steps.

A starting line was established so that the participant had to perform 4 gait cycles before reaching the force platforms to stabilize gait velocity. No other constraints were placed over the participants, which were instructed to walk normally at their preferred speed. If more than one foot was contacting the force platform or if a clear targeting behaviour was perceived by the researchers, the trial was discarded and a new one was performed without notifying the participant.

\section{Data processing}

The recorded motion data were pre-processed with the Qualisys
Track Manager (Qualisys AB, Sweden) software and the resulting data was exported to C-Motion's Visual3D (C-Motion, USA) for further analysis. The marker's trajectories were then filtered with a 6-Hz Butterworth low-pass filter and gait events (initial contact and pre-swing) were automatically identified with the software's proprietary routine. Ground reaction forces (GRF) were filtered with a $50-\mathrm{Hz}$ Butterworth low-pass filter to reduce some high-frequency parasitic signals encountered in the data. After this, the characterizing events of the anteroposterior, mediolateral and vertical force were signalled, and the zero-crossing moment of the anteroposterior force was identified as the midstance moment.

\section{Statistical analysis}

Data were statistically processed with IBM SPSS Statistics 22.0 (IBM Corporation, New York, USA). Descriptive statistics, average and standard deviation, were calculated for all variables using an average of lower limbs data. Before data inferential analysis, the normality of distribution was explored. Differences between groups were processed accordingly with a t-test or U-Mann Whitney. A multivariate analysis of variance was performed with a model of MANCOVA adjusted for age, height, weight and BMI. To verify whether spatiotemporal gait parameters could explain the neuropathy risk classification category, a linear regression analysis was performed. The significance level was set at 5\%.

\section{Results}

Lower values for age, weight, body mass index (BMI) and diabetes duration are found in the group without neuropathy (Table 1).

For all the spatiotemporal gait parameters studied (Table 2)

Table 2. Participants characteristics in both groups 0 and 2 IWGDF.

\begin{tabular}{|c|c|c|c|c|c|}
\hline & \multicolumn{5}{|c|}{ IWGDF Risk Classification } \\
\hline & \multicolumn{2}{|c|}{$\begin{array}{l}\text { (0) no peripheral neuropathy } \\
(\mathbf{N}=63)\end{array}$} & \multicolumn{2}{|c|}{$\begin{array}{l}\text { (2) peripheral neuropathy with peripheral } \\
\text { arterial disease and/or a foot deformity } \\
(\mathrm{N}=59)\end{array}$} & \multirow[t]{2}{*}{$p$} \\
\hline & Mean & Standard Deviation & Median & Standard Deviation & \\
\hline Cycle Time (s) & 1.10 & 0.14 & 1.23 & 0.17 & $<0.001$ \\
\hline Speed $(\mathrm{m} / \mathrm{s})$ & 1.18 & 0.10 & 0.90 & 0.17 & $<0.001$ \\
\hline Statures Per Second & 0.73 & 0.09 & 0.55 & 0.12 & $<0.001$ \\
\hline Stride Length $(\mathrm{m})$ & 1.29 & 0.13 & 1.09 & 0.13 & $<0.001$ \\
\hline Stride Width (m) & 0.11 & 0.02 & 0.13 & 0.02 & $<0.001$ \\
\hline Double Limb Support Time (s) & 0.22 & 0.05 & 0.30 & 0.10 & $<0.001$ \\
\hline Right Cycle Time (s) & 1.10 & 0.14 & 1.24 & 0.20 & $<0.001$ \\
\hline Right Initial Double Limb Support Time (s) & 0.11 & 0.03 & 0.16 & 0.05 & $<0.001$ \\
\hline Right Stance Time (s) & 0.65 & 0.09 & 0.77 & 0.14 & $<0.001$ \\
\hline Right Step Length (m) & 0.65 & 0.07 & 0.54 & 0.06 & $<0.001$ \\
\hline Right Step Time (s) & 0.55 & 0.07 & 0.61 & 0.08 & $<0.001$ \\
\hline Right Stride Length (m) & 1.29 & 0.14 & 1.10 & 0.18 & 0.003 \\
\hline Right Swing Time (s) & 0.44 & 0.05 & 0.48 & 0.13 & $<0.001$ \\
\hline Right Terminal Double Limb Support Time (s) & 0.11 & 0.03 & 0.15 & 0.05 & $<0.001$ \\
\hline Left Cycle Time (s) & 1.09 & 0.14 & 1.23 & 0.17 & $<0.001$ \\
\hline Left Stance Time (s) & 0.66 & 0.09 & 0.76 & 0.12 & $<0.001$ \\
\hline Left Step Length (m) & 0.63 & 0.07 & 0.54 & 0.06 & $<0.001$ \\
\hline Left Step Time (s) & 0.55 & 0.07 & 0.62 & 0.10 & $<0.001$ \\
\hline Left Stride Length (m) & 1.29 & 0.13 & 1.08 & 0.12 & $<0.001$ \\
\hline Left Swing Time (s) & 0.43 & 0.07 & 0.47 & 0.06 & $<0.001$ \\
\hline
\end{tabular}


statistical differences have been found between groups with the no peripheral neuropathy group showing a faster gait with higher cadence, greater stride and step length and less double stance time and stride width. To better compare speed between subjects' a variable that allows the normalization of the speed as it corresponds to the average speed divided by the subject height, statures per second, was also analyzed.

The regression model applied for the spatiotemporal gait parameters showed that $58 \%$ of peripheral neuropathy risk classification can be predicted ( $\mathrm{R}$ Square $=0.582945$ ) with statistical significance $(\mathrm{F}=26.557578 ; p<0.0001)$ by the stride width and length, the duration of the gait cycle, and the duration of the double limb support phase, as well as by the gait speed and the statures per second.

\section{Kinetics}

Anteroposterior, mediolateral, and vertical forces of the kinetic valid trials were normalized to the subjects' body weight and time normalized to the stance duration, as depicted in Fig. 1. Only the trials where all the foot was placed over the force platform were considered for this analysis. For statistical analysis, three descriptive instants of each plane GRF were compared between IWGDF risk classification groups as well as their moment of occurrence on the cycle. Statistical differences were found for most of GRF's amplitude (Pillai's Trace $=0.913 ; \mathrm{F}(18,40)=23.466 ; p<0.0001$ ) and time of occurrence variables (Pillai's Trace $=0.743 ; \mathrm{F}(18,40)=6.436 ; p$ $<0.0001$ ), with exception of the second anteroposterior and vertical ground reaction force instant for both limbs and the first anteroposterior and vertical ground reaction force instant for the right limb and the mediolateral ground reaction force instant for the left limb.

Peripheral neuropathy risk Group (2) shows a trend to produce less important GRF in amplitude and later in time throughout gait

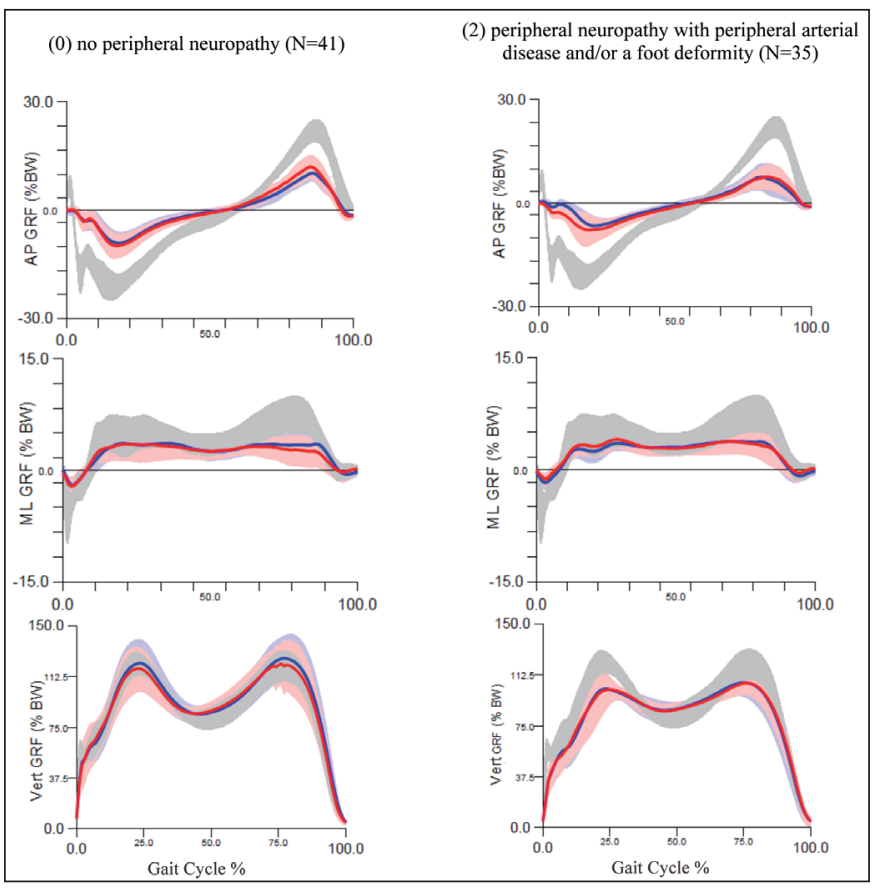

except for mediolateral forces which could contribute to the differences observed in speed and cadence.

\section{Kinematics}

Kinematics of each lower limb was analyzed in relation with three major gait moments, initial contact, midstance and pre-swing. Statistical differences were found for most variables in initial contact (Pillai's Trace $=0.950 ; \mathrm{F}(24,54)=42.35 ; p<0.0001)$, midstance (Pillai's Trace $=0.991 ; \mathrm{F}(24,13)=59.014 ; p<0.0001)$ and pre-swing (Pillai's Trace $=0.941 ; \mathrm{F}(24,55)=36.755 ; p<0.0001$ ). Pelvis and lower limb joint angles are presented in Fig. 2 for each group.

Ankle and knee are the joints where most differences between groups can be observed in all three gait moments studied, initial contact, midstance and pre-swing. During the initial contact, a

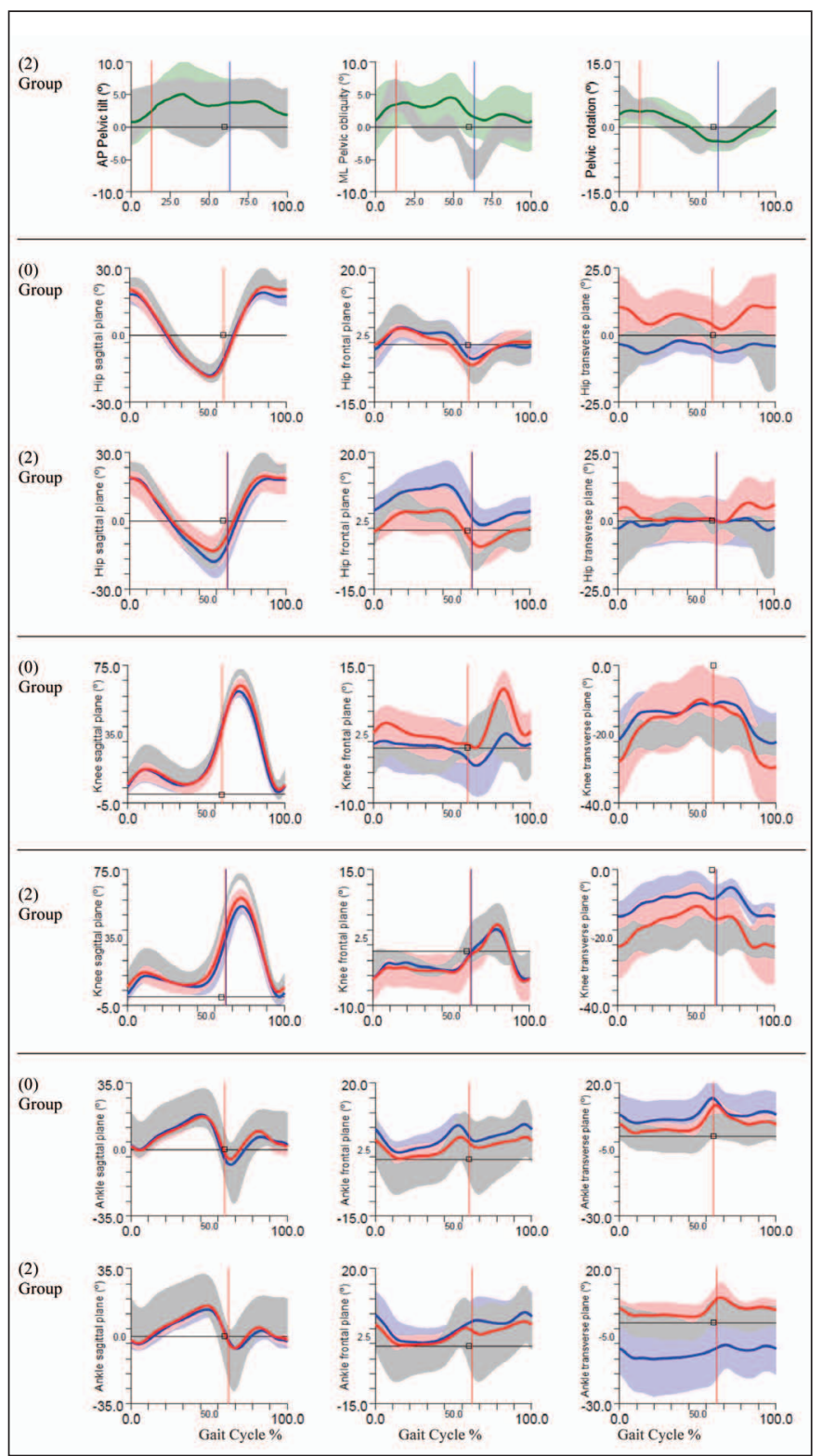

Figure 2. Average and standard deviation of all subjects Pelvis, Hip, Knee and Ankle movement in each group..

Right side is depicted in blue and left side in red. Red vertical line: Left pre-swing; Blue vertical line: Right pre-swing. Reference data from Labiomep normative data is depicted in grey; square: reference pre-swing. AP: anteroposterior, ML: mediolateral; ang: angle; AP Pelvic tilt angle (+ anteversion; -retroversion); ML Pelvic obliquity angle (+ right; - left); Pelvic rotation angle (+ right; - left), sagittal plane angle (+ flexion/dorsiflexion; - extension/plantarflexion); frontal plane angle (+abduction; adduction); transverse plane angle (+ internal rotation/pronation; - external rotation/supination). 
tendency for group 2 to walk with larger hip abduction and knee extension is observed. Ankle also tends to contact the floor with less dorsiflexion and in a more pronated position.

During the midstance ankle and knee joint positions in group 2 are particularly in greater adduction which could be a consequence of a greater base of support observed during the walk. The pre-swing moment is characterized by less hip and knee extension on the level 2 group risk.

\section{Discussion}

Most studies concerning diabetic gait analysis particularly evaluated parameters either associated with fall risk or with ulcer production. As several complications of diabetes precede major findings like ulcers, ${ }^{2}$ three-dimensional gait biomechanical analysis could be helpful to early detect health impairments related to diabetes. The aim of the present study was therefore to characterize the gait of people with diabetes in the early stages of the IWGDF classification risk and identify variables that can predict peripheral neuropathy.

Comparative observations of gait groups, with and without peripheral neuropathy, were performed. Gait was characterized in all three dimensions using a MoCap system and force platforms allowing to identify different movement patterns performed by groups. Our findings are consistent with the previously studied gait pattern associated with diabetic peripheral neuropathy, ${ }^{16-20}$ although a larger number of differences regarding early phases of illness development have been found. People classified on group 2 of the IWGDF can be identified by their lower speed and cadence during gait, as well as shorter step and stride length. A larger stride width and double stance time were also proved to predict the presence of peripheral neuropathy. Values found in both groups did not differ from ranges identified in previous studies. ${ }^{2,8,10,16,21}$ Groups' comparison showed statistically significant differences between most of the studied variables. Generally, a pattern of less movement and a spread base of support was found in our study in the initial contact, the midstance and the pre-swing on group 2 subjects. Accordingly, forces produced in this group tend to have a shorter magnitude and occur later during the gait cycle. In terms of energy conservation, this represents less efficiency, which can justify the relative slowness during the movement.

For this study, a motion analysis system was used to assess kinematics and kinetics of the gait, but spatiotemporal parameters are easily assessed with the use of a chronometer or a smartphone in a previously measured distance. The main importance of these findings is the fact that spatiotemporal parameters can be evaluated in the clinical environment without the need for major instrumentation, and they have a predictor value that should not be negligible.

On the other hand, the gait analysis demonstrates to be a powerful tool when detecting early modifications of three-dimensional biomechanical parameters and should be performed routinely in patients at risk.

Most studies involving kinetics focused on vertical forces. $^{2,10,16,18,20,22,23}$ In our study, all three planes were analyzed and the results show that also anterior-posterior force is an important variable. The peripheral neuropathy risk group shows a trend to produce less important GRF in amplitude and later in time throughout the gait, except for mediolateral forces which could contribute to the differences observed in speed and cadence. Figure 1. Average and standard deviation of all subjects anteroposterior (AP), mediolateral (ML) and vertical (Vert) GRF in each group.

Right side is depicted in blue and the left side in red. Reference data from Richards ${ }^{15}$ is depicted in grey.
MoCap approach of gait kinematics is not easily found in literature nor complete lower limb analysis. ${ }^{8}$ The most frequently used systems are usually accelerometers. ${ }^{20}$ Our study provided a full assessment of the pelvis and lower limb to better characterize the movement in all three planes. A range of gait motion differences has been found in the kinematics of both groups, especially concerning the knee and the ankle. It is also important to notice the joint position favoring the adduction in phases of greater weight bearing like midstance. Furthermore, reduced movement in the hip and knee do not allow an efficient movement during gait phase's transition.

Although a large number of trials have been conducted for this analysis the sample studied is reduced which is a limitation of the study. Another aspect is the fact that only 2 women participated even if one was in each group. Also considered a limitation is the sample wide characteristics, especially age and diabetes duration. For this study the vitamin B12 deficiency, that can affect diabetic patients on metformin ${ }^{24}$ was not assessed, which could too be considered a limitation.

\section{Conclusion}

To conclude, this study highlights the biomechanics differences in the gait of people with diabetes classified in different risk groups. The importance of spatiotemporal gait parameters is also revealed, demonstrating their capacity to identify the risk of peripheral neuropathy, which can help the general clinician to early identify the risk of neuropathy. Further studies with larger samples and exploring inverse dynamics and net joint moments are recommended.

\section{Acknowledgements/Agradecimentos}

FEDER through COMPETE - Programa Operacional Factores de Competitividade, and FCT - Fundação para a Ciência e a Tecnologia, under Project UIDB/00285/2020.

\section{Responsabilidades Éticas}

Conflitos de Interesse: Os autores declaram a inexistência de conflitos de interesse na realização do presente trabalho.

Fontes de Financiamento: Não existiram fontes externas de financiamento para a realização deste artigo.

Confidencialidade dos Dados: Os autores declaram ter seguido os protocolos da sua instituição acerca da publicação dos dados de doentes.

Proteção de Pessoas e Animais: Os autores declaram que os procedimentos seguidos estavam de acordo com os regulamentos estabelecidos pelos responsáveis da Comissão de Investigação Clínica e Ética e de acordo com a Declaração de Helsínquia revista em 2013 e da Associação Médica Mundial.

Proveniência e Revisão por Pares: Não comissionado; revisão externa por pares.

\section{Ethical Disclosures}

Conflicts of Interest: The authors have no conflicts of interest to declare.

Financing Support: This work has not received any contribution, grant or scholarship

Confidentiality of Data: The authors declare that they have fol- 
lowed the protocols of their work center on the publication of data from patients.

Protection of Human and Animal Subjects: The authors declare that the procedures followed were in accordance with the regulations of the relevant clinical research ethics committee and with those of the Code of Ethics of the World Medical Association (Declaration of Helsinki as revised in 2013).

Provenance and Peer Review: Not commissioned; externally peer reviewed.

\section{References / Referências}

1. Camargo MR, Barela JA, Nozabieli AJ, Mantovani AM, Martinelli AR, Fregonesi CE. Balance and ankle muscle strength predict spatiotemporal gait parameters in individuals with diabetic peripheral neuropathy. Diabetes Metab Syndr. 2015;9:79-84. doi: 10.1016/j.dsx.2015.02.004.

2. Maksimovic A, Hanewinckel R, Verlinden VJA, et al. Gait characteristics in older adults with diabetes and impaired fasting glucose: The Rotterdam Study. J Diabetes Complications. 2016;30:61-6. doi: 10.1016/j. jdiacomp.2015.10.006.

3. Andersen H. Motor dysfunction in diabetes. Diabetes Metab Res Rev. 2012;28 Suppl 1:89-92. doi: 10.1002/dmrr.2257.

4. Raspovic A. Gait characteristics of people with diabetes-related peripheral neuropathy, with and without a history of ulceration. Gait Posture. 2013;38:723-8.

5. IWGDF. Guidance on the prevention of foot ulcers in at-risk patients with diabetes. [Accessed 11 Mar 2016] Available from: http://iwgdf.org/guidelines/ definitions-criteria-2015/.

6. de Bruin ED, Hubli M, Hofer P, Wolf P, Murer K, Zijlstra W. Validity and reliability of accelerometer-based gait assessment in patients with diabetes on challenging surfaces. J Aging Res. 2012;2012:954378.

7. Hazari A, Maiya AG, Shivashankara KN, Agouris I, Monteiro A, Jadhav R, et al. Kinetics and kinematics of diabetic foot in type 2 diabetes mellitus with and without peripheral neuropathy: a systematic review and meta-analysis. SpringerPlus. 2016;5:1819. doi: 10.1186/s40064-016-3405-9.

8. Fernando M, Crowther R, Lazzarini P, Sangla K, Cunningham M, Buttner $\mathrm{P}$, et al. Biomechanical characteristics of peripheral diabetic neuropathy: A systematic review and meta-analysis of findings from the gait cycle, muscle activity and dynamic barefoot plantar pressure. Clin Biomech. 2013;28:831845. doi: 10.1016/j.clinbiomech.2013.08.004

9. Alam U, Riley DR, Jugdey RS, Azmi S, Rajbhandari S, D'Août K, et al. Diabetic Neuropathy and gait: a review. Diabetes Ther. 2017;8:1253-1264.

10. Allet L, Armand S, Golay A, Monnin D, de Bie RA, de Bruin ED. Gait characteristics of diabetic patients: a systematic review. Diabetes Metab Res Rev. 2008;24:173-91. doi: 10.1002/dmrr.809.
11. Barbosa M, Saavedra A, Severo M, Maier C, Carvalho D. Validation and Reliability of the Portuguese Version of the Michigan Neuropathy Screening Instrument. Pain Pract. 2017;17:514-21. doi: 10.1111/papr.12479. Epub 2016 Aug 19.

12. Wilken J, Rodriguez K, Brawner M, Darter B. Reliability and minimal detectible change values for gait kinematics and kinetics in healthy adults. Gait Posture. 2012;35:301-7.

13. Cappozzo A, Catani F, Della Croce U, Leardini A. Position and orientation in space of bones during movement: anatomical frame definition and determination. Clin Biomech. 1995;10:171-8.

14. Leardini A, Sawacha Z, Paolini G, Ingrosso S, Nativo R, MG. B. A new anatomically based protocol for gait analysis in children. Gait Posture. 2007;26:560-71.

15. Richards J. Biomechanics in Clinic and Research: An Interactive Teaching and Learning Course. Amsterdam: Churchill Livingstone/Elsevier; 2008.

16. Brown SJ, Handsaker JC, Maganaris CN, Bowling FL, Boulton AJ, Reeves ND. Altered joint moment strategy during stair walking in diabetes patients with and without peripheral neuropathy. Gait Posture. 2016; 46:188-193.

17. Deschamps K, Matricali GA, Roosen P, et al. Comparison of foot segmental mobility and coupling during gait between patients with diabetes mellitus with and without neuropathy and adults without diabetes. Clinical biomechanics (Bristol, Avon). Aug 2013 28(7):813-819.

18. DiLiberto FE, Tome J, Baumhauer JF, Quinn JR, Houck J, Nawoczenski DA. Multi-joint foot kinetics during walking in people with Diabetes Mellitus and peripheral neuropathy. J Biomech. 2015;48:3679-84. doi: 10.1016/j. jbiomech.2015.08.020.

19. Fernando ME, Crowther RG, Lazzarini PA, Sangla KS, Buttner P, Golledge J. Gait parameters of people with diabetes-related neuropathic plantar foot ulcers. Clin Biomech. 2016;37:98-107.

20. Gomes A, Onodera A, Otuzi M, Pripas D, Mezzarane R, Sacco I. Electromyography and kinematic changes of gait cycle at different cadences in diabetic neuropathic individuals. Muscle Nerve. 2011;44:258-68. doi: 10.1002/mus.22051.

21. Ko SU, Stenholm S, Chia CW, Simonsick EM, Ferrucci L. Gait pattern alterations in older adults associated with type 2 diabetes in the absence of peripheral neuropathy--results from the Baltimore Longitudinal Study of Aging. Gait Posture. 2011;34:548-52.

22. Najafi B, Wrobel JS, Grewal G, Menzies RA, Talal TK, Zirie M, et al. Plantar Temperature Response to Walking in Diabetes with and without Acute Charcot: The Charcot Activity Response Test. J Aging Res. 2012;2012:140968. doi: 10.1155/2012/140968.

23. Barn R, Waaijman R, Nollet F, Woodburn J, Bus SA. Predictors of barefoot plantar pressure during walking in patients with diabetes, peripheral neuropathy and a history of ulceration. PloS one. 2015;10:e117443.

24. Miyan Z, Waris N; MIBD. Association of vitamin B12 deficiency in people with type 2 diabetes on metformin and without metformin: a multicenter study, Karachi, Pakistan. BMJ Open Diabetes Res Care. 2020;8):e001151. doi: 10.1136/bmjdrc-2019-001151. 